\title{
Technology-mediated ELT Writing: Acceptance and Engagement in an Online Moodle Course
}

\author{
Hicham Zyad \\ Hassan II University, Morocco
}

\begin{abstract}
In the past fifteen years, Web 2.0 social networking technologies have ushered in a new era of information production, distribution and consumption with significant implications for language teaching and learning. An example of such technology is Moodle, which is a learning management system with several useful features that can transform the learning environment into a site for interactivity, connectivity and great amounts of extensive learning. With this in mind, the present case study aims to investigate tertiary education students' acceptance of and engagement in a Moodle-hosted writing course. Using case study methodology, qualitative data were elicited from 24 semester-two students on the basis of focus group interviews constructed in line with Technology Acceptance Model 2. Another source of data is Moodle log reports, which offered a detailed account of students' contributions and activities in the online writing course. The results showed that almost all the students perceived Moodle as a useful tool for sharing, collaboration and learning. The results also uncovered three different categories of students in terms of level of engagement; namely, highly engaged, moderately engaged and poorly engaged. The implications of these results for an effective implementation of Moodle are discussed.
\end{abstract}

Keywords: ELT; Moodle; Technology acceptance; Engagement; Blended writing course

\section{Introduction}

A pivotal issue in recent educational reform in Morocco is the gradual integration of ICT into mainstream teaching practices. The recommendations of this reform are outlined in the National Charter of Education and Training (1999). In article 10, the Charter calls for the integration of ICT in education by means of creating computer facilities in schools and universities in order to prepare the way for distance education and learning. A national action plan was drafted in 1998 and finalized in May 1999 in the midst of strong political will and the collaboration of a select committee of business leaders and representatives of the civil society. The educational authorities emphasized five salient themes deemed crucial in sustainable development and the effective use of ICT: education, governance, private sector development, e-commerce and access. Collectively, these themes constituted the basis for the national strategy for ICT development and were described as the e-Maroc plan. 
The Moroccan academia has also subscribed to this national project by conducting research on ICT integration in education with multiple foci. A line of such research has been exploratory by nature (Zyad, 2016a; Erguig, 2009) whereas other avenues of research have attempted to experiment with the emerging technologies to evaluate their relevance for achieving important pedagogical goals (Ouardaoui et al, 2012). Notwithstanding such mounting concern with ICT integration in education, a review of the literature reveals a scarcity of research investigating the affordances of Moodle as an environment capable of improving students' writing ability and allowing them a reasonable amount of autonomy in Moroccan post-secondary education. On another plane, most of the studies of technology on students' learning and engagement, be it Moodle or other forms of social media, lie on the quantitative end of the methodology spectrum. While purely quantitative studies offer statistics that can be generalized to other similar contexts, certain aspects of the learning environment under investigation may go unnoticed. It is not the objective of the present paper to downplay the importance of statistics-based quantitative research so much as it is to argue that the picture is more complex than it may appear to be in this type of empirical inquiry.

Accordingly and in line with the constructs of TAM2, this case study aims to empirically investigate semester-two students' acceptance of Moodle, based both on cognitive instrumental processes and social influence processes. The present study also seeks to explore the students' degree of engagement as measured by the amount of time spent in myriad Moodle-hosted activities, number of downloads from the platform and number of online feedback comments. These objectives were operationalized into two research questions:

1. To what extent do semester-two students accept Moodle-hosted activities and assignments in a blended writing course?

2. To what extent does Moodle increase students' engagement with writing activities and assignments?

The present paper begins by a review of the literature including the evolution of technology acceptance model together with research on students' engagement with technology. Subsequently, a detailed description of the methodology used is offered. After presenting the results, they will be discussed and related to previous research. Finally, the paper concludes with implications on how to implement Moodle-based activities more effectively.

\section{Review of the Literature}

\section{Technology Acceptance Model}

The literature abounds with theoretical models that aim to explain user acceptance of new information systems. Prominent among them is the Technology Acceptance Model (Davis, 1989), which is to date one of the predominant tools with acknowledged predictive power of user technology acceptance. This model has evolved over the years producing two distinct versions described in the subsections below.

TAM1 comprises five principal constructs: perceived usefulness, perceived ease of use, attitude, behavioral intention and actual use. To elucidate, two predictors of users' acceptance of a particular 
technology are users' perceptions of the ease of use and usefulness of such technology. Davis defines the construct of the ease of use as 'the degree to which the prospective user expects the target system to be free of effort' (Davis et al, 1989, p. 985). Usefulness can be defined as the users' perception as to the benefits that can be obtained from the implementation of a given technology. The former aspect of the model is said to influence the direction and strength of the latter. That is, if a given technology is perceived as free of effort, the user would deem it potentially useful. The first two constructs have an impact on attitude formation in the sense that they are conducive to developing in the user a positive or negative attitude towards the attitude object. For example, the user would hold a negative attitude if the innovation involves difficulty of use and is regarded as of little usefulness. Attitude is directly linked to the behavioral intention in that it makes the user ready to act favorably towards a certain information system. Finally, granting that all the previously mentioned elements favor the implementation of the technology in question, users would actually begin to utilize it in the routine of their everyday life.

With the emergence of new research-based evidence, Venkatesh and Davis (2000) modified TAM1 by adding other constructs broadly labeled as social influence processes and cognitive instrumental processes (See figure 1 below). Social influence processes include subjective norm, voluntariness and image. Subjective norm assumes that people held in high esteem by the user may influence the potential use of technology. That is, despite the initial reluctance to use an information system, the knowledge that highly regarded people (parents, teachers or even peers) do utilize such technology may encourage the user to utilize too. The second important construct in the new TAM version is voluntariness. As a matter of course, the use of technology can be either voluntary or mandatory. When it is mandatory, perceived usefulness and ease of use are relegated to a less important position. TAM2 also posits that the pursuit to maintain a good image within a reference group is another driver to use technology. It should be underscored that voluntariness and image mediate the relationship between subjective norm and intention to use technology.

In addition to perceived ease of use and usefulness, job relevance, output quality and result demonstrability constitute the cognitive instrumental processes of TAM2. The likelihood to use a particular system diminishes if the set of tasks that it performs are irrelevant to the context of use. Users of technology also form judgments about output quality. In other words, they evaluate how effectively the job-related tasks are accomplished by the information system. Initially, job relevance and output quality may seem to overlap but it should be stressed that they are two distinct constructs. For instance, two software programs may help achieve the same objective but the user may eventually decide to use only one of them because it is faster and more convenient. Finally, result demonstrability is the ability of the user to clearly associate the success in performing a given task to the use of the technology in question. Figure 1 below visually illustrates the structural components of TAM2

Several studies examined the acceptance of educational technology using TAM2. For instance, Venter et al (2012) provided more evidence that perceived ease of use and usefulness remain the most powerful determinants of technology user acceptance. They also confirmed that job relevance and facilitating conditions have an influence on students' behavior regarding the use of a learning management system. In an attempt to evaluate Korean students' acceptance of an e-learning environment in tertiary education, Park (2009) offered another strand of confirmatory evidence suggesting that perceived ease of use and usefulness are strong predictors of students' attitude 
towards e-learning. The study also contended that computer self-efficacy and subjective norm were found to have a significant effect on students' acceptance of technology. In the same vein, Jonas and Norman (2009) explored university students' behavioral intention to use textbook websites. They reported that usefulness, subjective norm and result demonstrability were strongly associated with students' intention to use textbook websites. However, the researchers argued that continual encouragement of the faculty is a facilitating driver to students' sustained motivation in using textbook websites.

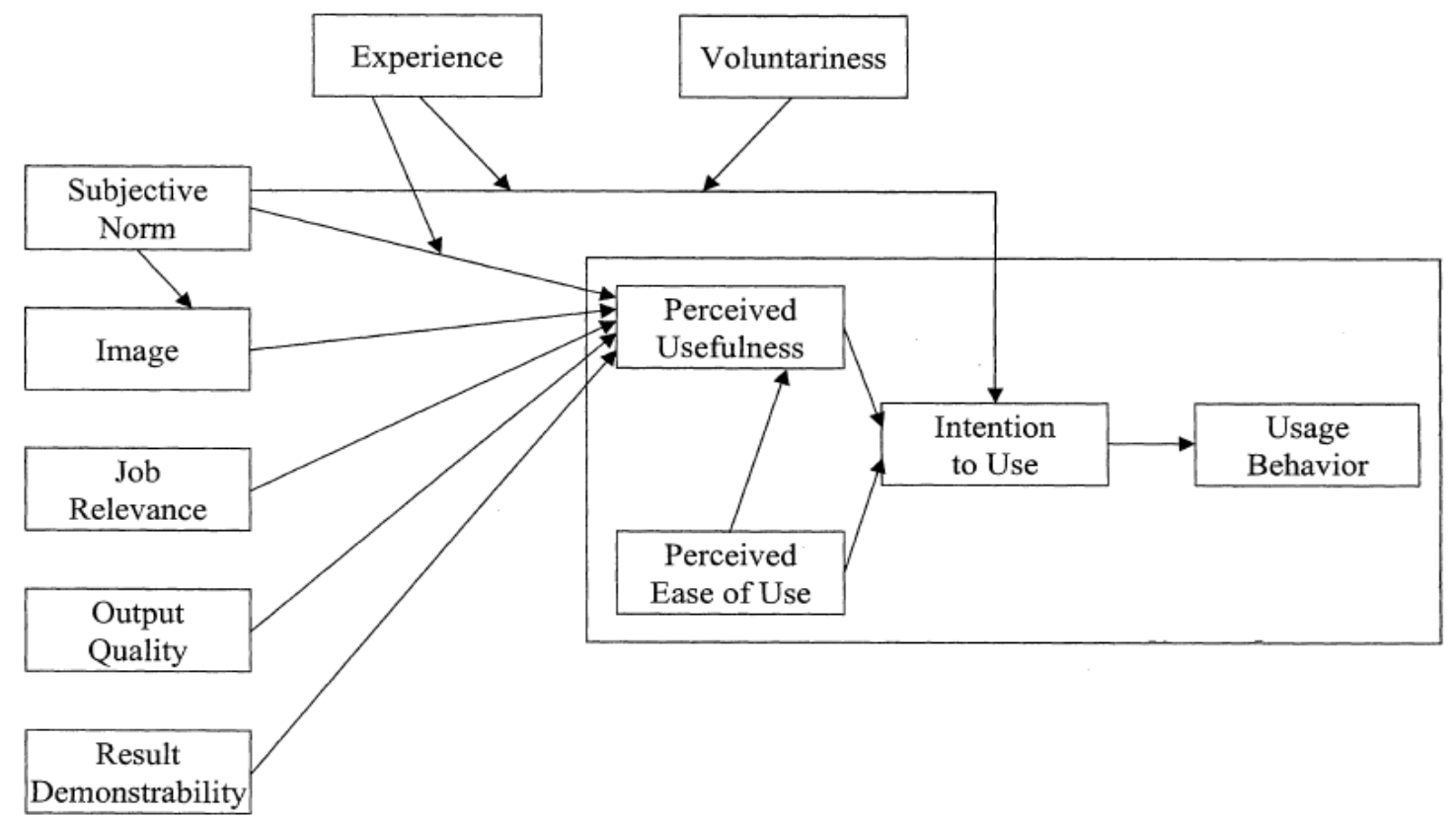

Figure 1: Technology acceptance model 2 (Venkatesh \& Davis, 2000, p. 188)

\section{Students' Engagement with Technology}

A strand of research has investigated the amount of students' engagement with different types of social networking technologies. Mason (2011) studied students' levels of engagement with an online discussion forum together with the factors that impede or encourage such engagement. The participants were given a short real-life problem to discuss in a virtual learning management platform. Although the task apparently was clear, the students' participation in the forum was minimal. This was ascribed to time constraints and lack of motivation, which in turn was pinned down to inadequately explaining the task to the students as well as failing to provide sustainable motivation. Additionally, the students complained that they felt demotivated due to insufficient moderation during the forum discussions. Besides, Junco et al (2011) explored the effects of Twitter on students' learning and engagement. The study utilized two treatment conditions with the experimental group using Twitter for several different types of academic and co-curricular discussions. The statistical measures indicated that the experimental group's engagement and grades were significantly higher than the control group. Content analysis of Twitter communications revealed increased levels of learning and engagement, exceeding those found in traditional forms of instruction. 
Furthermore, Parkin et al (2012) examined the impact of technology-supported forms of feedback on students' learning and engagement. The technical feedback-oriented interventions included electronic feedback with grades withheld, online publication of grades, criteria-based feedback and other more traditional methods of feedback. The results showed that the publication of students' grades online had a noticeable impact on their learning and increased the degree of engagement in future assignments. The students also expressed satisfaction with the automatic storage of feedback which they could revisit on other similar occasions. Another factor that increased students' engagement and learning is adaptive release of feedback and grades. It was found that sending feedback to students first to read and reflect upon before they were shown their grades was appreciated by the students. This practice enabled the students to concentrate more fully on the feedback offered and avoid the distracting effect of unfavorable grades.

However, not all studies reported that technology is always an aid to enhancing students' learning. A case in point is Neumann and Hood (2009), who investigated the effects of a wiki in a blended learning environment on university students' engagement and performance. The treatment group communicated the results of a practice report collaboratively using a wiki while the control group did the same task individually. Both conditions had the same effect on the students' knowledge of report writing as manifested in a later assignment that they wrote individually. The central finding in this study was that a wiki can improve students' engagement but not their learning. In the same vein, Ebner et al (2008) argued that previous research-based reports on the benefits of wikis on students' engagement and learning were usually conducted in mandatory settings where students had to act in response to incentives or pressure. With this in mind, they examined the effects of wikis on students' participation in a voluntary setting. It was found that none of the 287 participants published articles or edited those already posted during a whole semester.

\section{Methods}

\section{Context of the Study}

The study was conducted in Hassan II University, the School of Humanities in Ben M'Sik. The English department comprised around 300 semester-two students. One of the courses they had during the second semester was composition, which was designed to continue the work initiated in the first semester by going beyond the paragraph to study how to write a well-organized, coherent and unified narrative essay. The writing course was situated within a hybrid learning environment including both onsite and online compositional activities. The objectives of the course were to address micro-level issues related to grammar, spelling and mechanics as well as macro-level issues such as organization, content and development. The online activities were carried out in Moodle, a learning management system sponsored by the faculty administration. The students were required to download course materials from Moodle including videos, presentations, book chapters and worksheets. They were also required to post online the essays they wrote using the process approach in class in Moodle-based forums.

The researcher in the present study was in charge of the online platform. First, he was responsible for creating the course sections and uploading relevant supplementary materials for students to consult on the request of the main course teachers. Second, the researcher posted writing prompts 
for students to develop into well-written essays on a weekly basis. Another responsibility delegated to the researcher was to encourage the students to actively participate in the online platform by downloading materials and posting their essays online. Such encouragement can be described as bordering between voluntary and mandatory settings as it did not involve any enforcement or reward.

\section{Participants}

The present study included 24 semester-two students enrolled for English Studies at the Faculty of Letters and Humanities in Ben M'Sik. The participants were 14 female and 10 male students whose age ranged from 19 to 35 . The intervention period started from mi-February to mid-May with midterm and final exams at different intervals. Since the case study was part of a larger, quasiexperimental research design including three groups from two different universities, the participants were randomly selected and assigned to six groups who were supposed to collaborate and interact in response to online Moodle-based activities. On the basis of an online survey, it was found that two thirds of the participants had good computer literacy while one third stated that they were not as good as their peers. Arranging the students into six groups took into consideration their gender, level of computer literacy and language proficiency. Therefore, each group included male and female students with varying levels of computer literacy and language proficiency.

The rationale underpinning the decision to form groups of students with different characteristics is twofold. First, as has been previously indicated, the online course was designed to serve as a platform for the students to enhance their writing skills. Thus, assigning them to groups of four peers was meant to invoke the concept of scaffolding whereby high-achieving students assist their struggling counterparts in solving their language problems (Wood, Bruner \& Ross, 1976). In their turn, high-achieving students consolidate their understanding of writing issues by reviewing their peers' work and offering formative feedback (Zyad, 2016b). Second, actively engaging in Moodle necessitates a reasonable degree of computer literacy. Some students may drop out of the course because of repeated failures at using the online platform. For this reason, heterogeneous groups with students of varying computer skills mastery was deemed useful in order to help their less skilled peers as the need arises.

\section{Instructional Procedures}

The study was conducted in a blended writing course including both onsite and online activities. The onsite part of the course was based on the process approach to writing. Each two-hour session was divided into theoretical and practical components. About a third of each session was devoted to interactive discussions about numerous writing areas including essay structure, sentence structure, fragments, run-ons, modifiers and other related issues. The students were notified of the topic to be tackled in the following session so as to consult the materials in Moodle and get ready for the inclass discussions. The remaining two thirds went to the writing of an essay using the stages of the process-based approach. Having written the first draft, the students were required to post the draft online and open up discussions about one another's work. 


\section{Data Collection and Analysis}

The decision to use case study methodology was based on the understanding that this form of inquiry "can penetrate situations in ways that are not always susceptible to numerical analysis" (Cohen, 2000, p. 181). Although case studies are usually located at the interpretive end of the methodology spectrum, it is not uncustomary to find that they also include numerical data analysis. With this in mind, despite devoting the greatest part to qualitative analysis, the present case study collected and analyzed quantitative data as well. Therefore, three data collection tools were utilized, namely focus groups, an online Moodle-generated survey and Moodle activities reports. As pointed out earlier, TAM 2 (Venkatesh \& Davis, 2000) was drawn upon in order to formulate the questions for the focus group interviews.

The online Moodle-generated survey was designed to elicit participants' demographics as well as information about their engagement with technology for purposes other than learning, ICT training and accessibility. The 24 participants were divided into groups of four to interact and collaborate in Moodle-based activities. The focus group interview was conducted with each group separately at different intervals. The researcher made sure to transcribe the tape-recorded interviews immediately so as to capture important moments while they were still vivid. After all the transcripts were ready, they were subjected to rigorous qualitative analysis and coding with a view to extracting themes and categories as well as establishing possible relationships among them. The Moodlegenerated log-in activities reports were organized using descriptive statistics.

\section{Results}

\section{Students' Acceptance of Moodle}

\section{Cognitive Instrumental Processes}

Of the 24 participants, 11 indicated that they had absolutely no difficulty in using Moodle. They all agreed that Moodle seemed to be especially designed to be used by individuals with relatively moderate mastery of computer skills. Following are some of the comments made by the students on this issue:

\section{S1: "As I see it, Moodle is a piece of cake!"}

S2: "Well, what I like about Moodle is that it did not take me long to get along with most of its features"

S3: "For me, downloading materials, dragging files, posting comments are things you find in other social media applications....there is nothing unfamiliar to learn about Moodle"

However, seven students expressed their frustration with regard to the enrolment process. At the beginning, the students had to create an excel file filled with information such as their first and last name, email account, city and country. The researcher had to take the excel file to the administrator to generate passwords and usernames. This strategy failed as it led to the emergence of several technical problems and was later replaced by self-enrolment. One of the seven students complained 
that, "When I wanted to log in, I was told that he needed to register first although I already did." Another student agreed with her group-mate and explained that, "It was not until the enrolment process was changed into self-enrolment that I could enroll successfully in Moodle." Still another said that, "I was driven to feel disinterested in the writing course when I repeatedly attempted to log in but in vain."

Almost all students, $(n=20)$ perceived Moodle as a useful tool for collaborative writing activities. They concurred that the weekly posting of their written assignments and the discussions that ensued appeared to have a good impact on their learning. Additionally, they felt that extending their composition course beyond class time was a useful way to make them more motivated. Among the benefits that received unanimous agreement was the multi-media files uploaded into the platform such as videos, PowerPoint files, book chapters and worksheets on different writing areas. About two thirds of the students said that they could access the course any time anywhere to check newly posted materials and new home assignments. Below are some of the comments made on the perceived usefulness of Moodle:

S1: "I think that Moodle is really helpful as it enabled me to keep connected with my classmates" S2: "I used to do my assignments alone, which was boring. With Moodle, it is exciting to get support from my friends to complete assignments"

S3: "Moodle led me to feel that my classmates care about my writing problems"

S4: "It is cool to get easy access to so many materials without so much pain"

Moreover, students' judgments as to the extent to which Moodle and the activities it contained were relevant to composition skills development were generally positive. More than two thirds of the students $(n=21)$ stated that Moodle is highly relevant to improving their writing ability. They perceived such activities as holding online discussions on the writing issues and problems with which they were grappling and providing feedback on one another's written assignments as practices that were conducive to raising their noticing ability. In this respect, a student said, "I liked it when I got feedback from my partners. In fact, this sort of feedback helped me see problems I had in his writing that I could not have noticed without such feedback." Another student added, "When I read my partners' work, I had the chance to see how they dealt with the topic from different angles. I also benefitted from the vocabulary I learnt from their writings."

On the question of how well Moodle performed tasks relevant to the writing course in an attempt to address output quality, the greatest majority of the students emphasized that Moodle is qualitatively different from other online tools that can be used for similar purposes. If job relevance is related to how compatible a given system is with the set of tasks being done, output quality aims to test the degree of profitability of the system in comparison to other systems. Among the answers obtained is the sample below:

S1: "If I were to choose from among different online writing tools, I would choose Moodle" S2: "Moodle is better because it contains different options in one place. You have blogs, forums, and workshops in the same platform"

S3: "I have never used a platform that includes so many activities and options" 
Additionally, result demonstrability failed to show any importance in driving students to perceive Moodle in a positive light. The results germane to this area can be divided to three different categories. The first category is associated with students $(n=15)$ who still felt that they had more issues to resolve in their writing. In other words, they felt that they did not make so much progress as to identify it with Moodle. The second category of students $(n=7)$ felt that they made measurable headway in their writing but they attributed it to factors extraneous to Moodle. They argued that it was not Moodle per se that helped them improve. Among the factors they invoked were the extensive reading they made and the process writing activities as well as the writing lessons they had in class. The third category $(n=2)$ lauded Moodle as the principal culprit in the progress they made in their compositional skills.

\section{Social Influence Processes}

Students' responses polarized as to the importance of subjective norm as a factor that encouraged them to use Moodle. About 9 students thought that it was absurd for them to use Moodle or any other information system only because someone else was using it, no matter how much they respected them. This seemed to have hurt their sense of autonomy and maturity. They wanted to be seen as independent in making decisions about the technological tools and devices that they employed for learning purposes. In this respect, a student commented that "I do not need anyone to tell me what is or what is not useful for me. The only way to know for sure is by testing it out." Another respondent indicated that "it is not always true that what people say is good is actually so". By contrast, the rest of the students stated that it was always judicious to seek advice from more experienced people. They all agreed that if their instructor judged a given didactic tool as worth using, they would have to use it as well. A student explained that "more experienced people like teachers and parents are in a better position to judge the utility of a given practice. So why not simply follow their guidance?"

In response to the question of the impact of image on the decision to use Moodle, 17 students reported that it was important for them to be seen in a positive light by their peers, parents and teachers. For them, being in the $21^{\text {st }}$ century implies that one is supposed to be conversant with all sorts of technologies. In this regard, an interviewee said that "your image is certainly undermined when you cannot deal effectively with a platform as easy as Moodle." They believed that it would undermine their status as digital natives if their peers and the teacher knew that they could not engage in the Moodle-based online writing course. The remaining seven students had a different view of image. They emphasized that they never associated the use of Moodle with a good image. They seemed to agree that it was more salient to improve their writing ability than to enhance one's image by being able to use Moodle.

As regards voluntariness, all the respondents agreed that the question of whether or not Moodle is an optional part of the writing course plays a decisive role in their engagement levels. They all agreed that although engagement in Moodle was an interesting experience, it required more efforts on their part to continually check out new announcements, download materials, contribute to group discussions, and post written assignments. Besides the learning from which they benefitted, they emphasized that a portion of the final grade in the course should have been allocated to the extent to which each student participated in the different online activities. 


\section{Students' Engagement in Moodle}

For convenience, the 24 students were arranged into 6 groups whose engagement in Moodle is summarized in table 1 below.

Table 1. Engagement in Moodle as Measured by Downloads, Uploads, Comments and Number of Hours Online

\begin{tabular}{lccc}
\hline Groups & Activities & Means & Standard deviations \\
\hline G1 & Downloads & 39 & .18 \\
& Uploads & 28 & .07 \\
& Comments & 293 & .33 \\
GH2 & NHO* & 14 & .12 \\
& Downloads & 27 & .56 \\
& Uploads & 23 & .77 \\
G3 Comments & NHO* & 82 & .23 \\
& Downloads & 9 & .53 \\
& Uploads & 31 & .89 \\
G4 & Comments & 18 & 1.9 \\
& NHO* & 91 & .69 \\
& Downloads & 8.5 & 1.7 \\
& Uploads & 34 & .65 \\
G5 & Comments & 11 & .89 \\
& NHO* & 82 & .60 \\
& Downloads & 9.5 & .73 \\
& Uploads & 15 & .48 \\
G6 & Comments & 7 & 1.05 \\
& NHO* & 54 & 1.49 \\
& Downloads & 6.5 & 1.59 \\
& Uploads & 7 & 1.78 \\
& Comments & 2 & 2.10 \\
& NHO* & 12 & 1.53 \\
& & 3.5 & 1.54 \\
\hline
\end{tabular}

NHO*: Number of hours online

As can be observed from table 1, students' engagement in the various Moodle-based activities differs from one group to another. The analysis of the data obtained from Moodle log reports identified three categories of engagement: highly engaged, moderately engaged and poorly engaged. Group one can be labeled as highly engaged due to the intense activities they performed in terms of number of comments $(\mu=293)$ as they exchanged feedback on their writings and the number of downloads $(\mu=39)$ and uploads $(\mu=28)$ they made over the semester. The highest mean for the number of hours spent online was also suggestive of the high engagement displayed by this group. Besides, the standard deviations associated with this group demonstrated that the students' amount of engagement was approximately equal. That is, all the students in the group participated in the online platform on an equal basis without being much too dependent on a given member. 
As regards the second category of engagement, groups 2, 3, and 4 were moderately engaged. Their download means ranged from 27 to 34; their upload means from 11 to 23; and their number of comments means from 81 to 91 . Although the three groups were classified as moderately engaged, a reading of the standard deviations associated with each engagement measure reveals that some students were more engaged than others. For instance, the standard deviation representing the number of hours spent online for group three is 1.7, which indicates that some students were more actively engaged in Moodle than their group-mates.

The poorly engaged groups were 5 and 6 . The number of uploads they effected as part of their online collaborative work was as low as $\mu=2$ and the number of hours spent online dropped to $\mu=3.5$ in comparison to the other groups. Across the two poorly engaged groups, the means for the number of comments they exchanged ranged from 12 to 54, suggesting that they were not interested in the online discussions on their written productions. Again, an examination of the standard deviations of these two groups clearly shows that the small means obtained do not even reflect that the students contributed equally to the multiple Moodle-based activities.

To examine the ways in which the students' activities in Moodle developed over the semester, data were collected at three different intervals, namely in the second, sixth and tenth weeks. The means and standard deviations in table 2 corroborated the observations made in the previous table regarding the pattern of activity within each group of participants. Again, group 1 came on top of all the other groups in terms of the high levels of engagement in the various online activities as witnessed the high mean gains and relatively small standard deviations across the intervention period. Coming second in terms of intensity of engagement were groups 2,3 , and 4 . These three groups were categorized as moderately engaged due to the palpable difference in means in comparison with group 1 . It should nonetheless be pointed out that group 1 and groups 2, 3, and 4 were similar al the level of small standard deviations within each group. However, groups 5 and 6 were ranked as the least active groups because of the small means associated with each activity and the uneven contributions of each member as can be deduced from the large standard deviations.

Table 2. The Pattern of Activity in Moodle for All the Groups Across Three Time Intervals

\begin{tabular}{lcccc}
\hline Activities & Groups & Second week & Sixth week & Tenth week \\
\hline \multirow{3}{*}{ Downloads } & & M \& SD & M \& SD & M \&SD \\
\cline { 2 - 4 } & 1 & $41(.34)$ & $37(.13)$ & $28(.31)$ \\
& 2 & $19(.34)$ & $24(.24)$ & $29(.56)$ \\
& 3 & $26(.16)$ & $32(.25)$ & $29(.42)$ \\
& 4 & $29(.45)$ & $25(.19)$ & $36(.32)$ \\
Uploads & $10(.78)$ & $7(1.14)$ & $7(.98)$ \\
& 6 & $6(.1 .22)$ & $7(.97)$ & $10(.1 .02)$ \\
& 1 & $30(.27)$ & $23(.56)$ & $25(.47)$ \\
& 2 & $15(.88)$ & $16(.76)$ & $23(.88)$ \\
& 3 & $12(.65)$ & $16(.66)$ & $19(.48)$ \\
& 4 & $9(.87)$ & $10(.59)$ & $8(.38)$ \\
& 5 & $4(.99)$ & $8(1.5)$ & $5(.78)$ \\
& 6 & $3(.60)$ & $5(.48)$ & $3(1.4)$
\end{tabular}




\begin{tabular}{llccc} 
Comments & 1 & $287(.09)$ & $260(.14)$ & $301(.12)$ \\
& 2 & $57(.76)$ & $88(.85)$ & $81(.45)$ \\
Number of hours & $72(.53)$ & $89(.23)$ & $95(.56)$ \\
& 4 & $67(.34)$ & $87(.66)$ & $75(.56)$ \\
& 5 & $41(.87)$ & $60(.87)$ & $23(.67)$ \\
& 6 & $16(1.3)$ & $9(.79)$ & $19(1.01)$ \\
& 1 & $14(.43)$ & $9.5(.23)$ & $10(.12)$ \\
& 2 & $4(.67)$ & $10(.77)$ & $7(.85)$ \\
& 3 & $5(.44)$ & $8.5(.86)$ & $7(.33)$ \\
& 4 & $8.5(.55)$ & $10(.65)$ & $7.5(.66)$ \\
\hline M = mean / SD = Standard deviation & $3.5(.99)$ & $4.5(.89)$ & $3(.40)$ \\
\hline
\end{tabular}

For convenience of exposition, only three groups representative of each category were selected for comparison purposes. Figure 1 graphically represents the amount of engagement for group one, two and six over the semester:

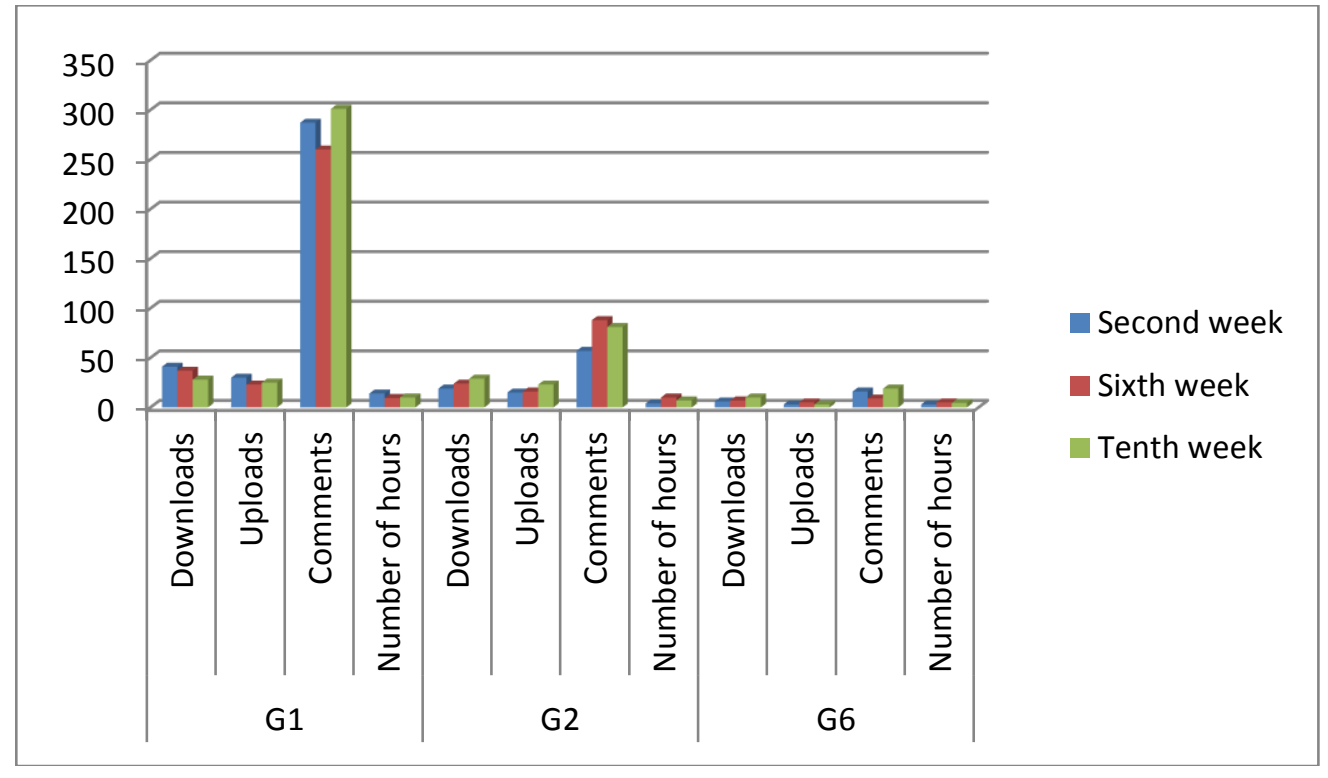

Figure2. Engagement in Moodle for Groups 1, 2 and 6 over the Semester

This graph visually illustrates the differences between the highly engaged, the moderately engaged and the poorly engaged groups. The highest bars in group 1 reveal the degree of engagement and the amount of collaborative discussion that went on within this group. Although group two is far much behind group 1, it was comparatively far ahead of group 6 . This can readily be observed by examining the bars standing for the number of comments together with the amount of time spent online. 


\section{Discussion}

\section{Students' Acceptance of Moodle}

The present study explored semester-two students' acceptance of Moodle from a qualitative perspective in addition to their levels of engagement in the online, Moodle-based part of a blended writing course.

\section{Cognitive Instrumental Processes}

Concerning cognitive instrumental processes, the results suggested that the majority of the students did not perceive any serious difficulties vis-à-vis Moodle features. The only exception was in the enrolment process, which was later solved by switching into students' self-enrolment. All the students considered Moodle as a useful online platform for extended collaboration in their quest to enhance their writing skills. Almost all the participants thought that Moodle and the activities it offered were highly relevant to the writing course. On the question of the profitability of Moodle, all the students agreed that it performed far better in comparison to other online platforms. The index of result demonstrability revealed that students' were not of the same opinion as to the impact of Moodle on their writing development.

It appears that cognitive instrumental processes play a salient role in determining students' acceptance of Moodle as an online educational space for interaction and collaboration. Perceived ease of use and usefulness continue to be decisive factors in encouraging students to adopt a certain technology for learning purposes. For instance, when the students experienced difficulty in the enrolment process, it threatened to negatively impact their motivation to actively engage in Moodle. Additionally, the simplicity of the interface and variety of activities incorporated within a single platform all contributed to students' preference of Moodle over other similar systems.

However, the complexity of the learning process emerged with regard to result demonstrability. In this respect, students' perceptions diverged into three categories. Some students did not view Moodle as ultimately helpful in improving their writing skills although they perceived it as both easy and useful. The way this group of students perceived Moodle seems to suggest that it can exclusively lead them to a higher level of writing proficiency without taking account of other factors such as the instructor and the onsite part of the course. A different but more balanced view is embraced by the second category of students, who argued that the progress they made is attributable to a combination of factors including Moodle-based activities, extensive readings and the onsite part of the course. On another extreme, the third group directly associated the progress they made with Moodle. This disparity in students' perceptions of the part played by Moodle in enhancing their writing ability brings to the fore the contribution of other factors that goes unnoticed in large-scale quantitative studies.

In consonance with previous studies, cognitive instrumental processes continue to constitute fundamental determinants of technology user acceptance. To exemplify, Venter et al (2012) found that the constructs of ease of use and usefulness together with job relevance were significant predictors of students' acceptance of a learning management system. However, result 
demonstrability was found significant in Jonas and Norman (2009) while the present study reported that not all the students directly associated the progress they made in writing with Moodle-based activities. On the whole, it seems that cognitive instrumental processes are strong determinants of users' acceptance of technology.

\section{Social Influential Processes}

Regarding this area of TAM2, the present study found that subjective norm was not viewed as an essential determinant of students' intention to use Moodle. The students stated that they suspended any judgments as to the utility of Moodle until they themselves experimented with it. That is, the verdict they aspired to reach was not supposed to be based on second-hand experiences. This attitude is not uncommon in semester-two students as they always want to be seen as independent and rational. This actually goes hand in hand with the spirit of constructionism, which calls for experiential, hands-on construction of knowledge. However, other studies including Venkatesh and Davis (2000) found that subjective norm strongly predicted users' behavior towards technology. Park (2009) reported that subjective norm strongly influenced students' behavioral intention to use e-learning. This discrepancy in the results on subjective norm may be traced down to cultural differences among the participants in the respective studies. The influential opinion of highly regarded individuals may vary from one cultural context to another. This may explain why the construct of subjective norm has continually appeared and disappeared in successive models of technology acceptance.

Strangely enough, although image and subjective norm are tightly related, the present study presented dissimilar results on their influence on students' acceptance of Moodle. It was found that the students were concerned about the way they were perceived by members of their community with regard to their computer and technology literacy. Notwithstanding the indifference they displayed in relation to valued members of society, the effort to maintain a good image compelled the students to take measures to join the Moodle-based collaborative activities. Venkatesh and Davis (2000) included the construct of image in TAM2 as it significantly predicted users' acceptance of technology.

Furthermore, the present study highlighted the determining role of voluntariness in influencing students to employ Moodle. Jonas and Norman (2009) reported that students' decision not to use textbook websites was shaped and informed by the construct of voluntariness. Because they were working under time constraints, they had to organize their priorities. Since the use of textbook websites was optional, it was perceived as a low priority and thus the students chose not to use them. While this is somehow similar to what was reported in the current case study, the students suggested that the incorporation of a reward or some form of incentive can bolster voluntary settings.

\section{Students' Engagement in Moodle}

Despite the generally positive attitude the students expressed in relation to Moodle, their log-in records uncovered three different patterns of engagement. Being highly and moderately engaged, 
groups from one to four illustrate how useful learning management systems can be in extending students' discussions and course activities beyond class time. Although the objective was not to evaluate students' attainment as a function to exposure to online collaborative activities, it is assumed that such a learning environment is potentially beneficial to students. The instructor can always monitor students' work outside of the classroom. Besides, the acceptable threshold of engagement reached by the students in the present study is inconsistent with Ebner et al (2008), who argued that engagement in e-learning was reported to be high in previous research because it was conducted in mandatory settings. However, it can be suggested that engagement could have been far greater if the students had been promised a reward for the efforts they invested in Moodle.

It should be pointed out that groups five and six did not show as much interest in Moodle as reflected by the smaller figures of their log-in records. Although they expressed their acceptance of the online platform and were satisfied by its features, these two groups failed to translate such an attitude to active engagement. This brings up the issue of the inadequacy of self-reported data. The inconsistency between the students' stated acceptance of Moodle and their limited engagement can be explained by their attempt to maintain a good self-image among their peers and instructor. This may be supported by the finding that they wanted to use Moodle only because they did not appreciate the prospect of being seen as computer illiterate or ignorant of basic technological tools. Moreover, it was observed in groups five and six that some students were more actively engaged than their group-mates. It is understandable why this engagement started to decline as less engaged students started to exert a negative impact on their more engaged peers.

\section{Conclusions and Implications}

Contrary to the widespread examination of technology acceptance model through the lens of quantitative inferential statistics, the present study explored a group of semester-two students' acceptance of Moodle as part of a blended writing course from a qualitative perspective. The study also examined the level of students' engagement in Moodle over a semester on the basis of their log-in reports. The results showed that cognitive instrumental processes were deemed powerful indices of students' intention to use Moodle. The exception was result demonstrability, which polarized students' opinions into three categories. Regarding social influence processes, subjective norm was perceived to be an unimportant factor in shaping students' attitudes towards Moodle. However, image was found to be a highly influential variable since the students did not want to be seen as less competent than their peers. Besides, the study reported that engagement was not evenly distributed among the six groups. It was also found that motivation started to decline over time due to the lack of incentives.

In light of the results obtained in the present case study, the following implications are in order. Given the uninterrupted increase of tertiary education students, official measures have to be taken to accommodate them. A possible efficient strategy is to alleviate the pressure on classrooms by using learning management systems such as Moodle. However, for students to accept Moodle as part of their learning environment, the educational authorities need to organize training programs for students to raise their technology literacy. It was pointed out earlier that difficulty of use may have counterproductive outcomes, leading to students' refusal to engage in technology-mediated learning. Remember the confusion alluded to earlier in the study about the enrolment method that 
did not work. This technical issue might have affected the students negatively. Thus, these programs should aim to sensitize students to how Moodle can boost their learning better than traditional tools of instruction. When students become technology literate, they will appreciate the degree of profitability to be gained from Moodle and thus will never worry about their image. Moreover, to sustain the same level of engagement from the outset of the semester to its end, instructors are called upon to provide concrete incentives to students in return for the efforts they invest in the online collaboration. Instructors are also required to maintain constant social presence in the platform to encourage students' with less interest and probe the reasons for their lack of motivation.

\section{References}

Cohen, L., Manion, L., \& Mor, K. (2000). Research methods in education. London: Routledge.

Davis, F. D. (1989). Perceived usefulness, perceived ease of use, and user acceptance of information technology. MIS Quarterly, 13(3), 319-339.

Ebner, M., \& Kickmeier-Rust, M. (2008). Utilizing Wiki-Systems in higher education classes: A chance for universal access? Univ Access Inf Soc(7), 199-207.

Erguig, R. (2009). The use of information technologies and audiovisual media in ELT: The department of English in El-jadida, Morocco, as a case study. Porto Linguarum, 11, 115-128.

Helen J. Parkin, J. H., Hepplestone, S., Holden, G., Irwin, B., \& Thorpe, L. (2012). A role for technology in enhancing students' engagement with feedback. Assessment \& Evaluation in Higher Education, 37(8), 963-973.

Jonas, G. A., \& Norman, C. S. (2011). Textbook websites: User technology acceptance behaviour. Behaviour \& Information Technology, 30(2), 147-159.

Junco, R., Heiberger, G., \& Loken, E. (2011). The effect of Twitter on college student engagement and grades. Journal of Computer Assisted Learning, 27, 119-132

Mason, B. R. (2011). Student Engagement with, and Participation in, an e-Forum. Educational Technology \& Society, 14(2), 258-268.

Ministry of National Education in Morocco. (1999). National Charter of Education and Training. Retrieved on 14 February 2014, from http://www.cse.org.ma/ar/admin_files/ressources/ charte-men_ar.pdf

Neumann, L. D., \& Hood, M. (2009). The effects of using a wiki on student engagement and learning of report writing skills in a university statistics course. Australasian Journal of Educational Technology, 25(3), 382-398.

Ouardaoui, A., Legrouri, A., Darhmaoui, H., \& Loudiyi, K. (2012). ICT integration into chemistryphysics classes in middle schools through a participatory pilot project approach. Procedia: Social and Behavioural Sciences, 55, 232-238.

Park, S. Y. (2009). An analysis of the technology acceptance model in understanding university students' behavioral intention to use e-Learning. Educational Technology \& Society, 12(3), 150-162. 
Venkatesh, V., \& Davis, F. (2000). A theoretical extension of the technology acceptance model: Four longitudinal field studies. Management Science, 46(2), 186-204.

Venter, P., van Rensburg, J. M., \& Davis, A. (2012). Drivers of learning management system use in a South African open and distance learning institution. Australasian Journal of Educational Technology, 28(2), 183-198.

Wood, D., Bruner, J. S., \& Ross, G. (1976). The role of tutoring in problem solving. Journal of Child Psychology and Psychiatry and Allied Disciplines, 17, 89-100.

Zyad, H. (2016a). Integrating computers in the classroom: Barriers and teachers' attitudes. International Journal of Instruction, 9(1), 67-78.

Zyad, H. (2016b). L2 writing development: The case of two high-achieving and two struggling college-level students. International Journal for 21st Century Education, 3(1), 25-36.

Correspondence: Hicham Zyad, The Moroccon-American Studies Doctoral Program, English Department, School of Humanities, Hasan II University, Ben M'sik, Morocco. 